\title{
A CASTRAÇÃO E SEUS EFEITOS ESTILÍSTICOS: DA PARRESIA FOUCAULTIANA A UMA POSTURA PSICANALÍTICA
}

Amos Squverer

Amos Squverer
Psicanalista,
encarregado
de cursos na
Université Paris
7 Denis-Diderot,
pesquisador
associado ao Centre
de recherche
psychanalyse,
médecine et
societé, psicólogo
clínico no Hospital
Sainte-Anne, doutor
em antropologia
psicanalítica.

Amos Squverer de cursos na Université Paris 7 Denis-Diderot, pesquisador associado ao Centre de recherche psychanalyse médecine et societé, psicólogo no Hospital em antropologia

\begin{abstract}
RESUMO: Este artigo situa a castração como ponto fundamental de divergência entre Foucault e a psicanálise. Em primeiro lugar, tratase de abordar a crítica de Foucault à psicanálise para apreender a especificidade desta última. Em seguida, busca-se demonstrar como a castração conduz a psicanálise e Foucault para duas posturas fundamentalmente diferentes do verdadeiro-dizer. A parresia permite indicar para o psicanalista, pelo seu avesso, as coordenadas de uma possível postura para sustentar a causa analítica. A estilística da existência esclarece, pelo seu avesso, o estilo analítico.
\end{abstract}

Palavras-chave: Foucault, parresia, castração, estilo, verdade.

\begin{abstract}
Castration and its stylistic effects: From Foucault's parrhesia to a psychoanalytic posture. This article seeks to place castration as the fundamental point of difference between Foucault and psychoanalysis. First, we will learn the Foucault's criticism to psychoanalysis in order to grasp the originality of the later. Secondly, the author seeks to show how castration leads psychoanalysis and Foucault to two fundamentally different positions of say-truth. For the psychoanalyst, Parrhesia identifies, by its reverse coordinates, a posture that supports the analytic discourse. The stylistics of existence clarifies, by its opposite, the analytic style.
\end{abstract}

Keywords: Foucault, parrhesia, castration, style, truth. 


\section{INTRODUÇÃO}

Propomos voltar nosso olhar para Foucault, na medida em que este autor nos permite indicar uma especificidade da psicanálise a partir de seu avesso. Foucault, por meio da crítica que dirige à psicanálise, permite entrever, de maneira edificante, sua especificidade. Ao longo do desenvolvimento desta crítica, veremos como seu diálogo com a psicanálise parece se chocar com o rochedo da castração.

Em um segundo momento, mostraremos como este ponto de divergência conduz Foucault e a psicanálise a adotarem duas posições e dois estilos diferentes do verdadeiro-dizer — consequência inevitável deste ponto de divergência. Certamente, o posicionamento ético do filósofo foucaultiano, sua ação na cultura e sua posição política, têm por objetivo realizar "A ontologia histórica de nós mesmos” (FOUCAULT, 1984/2001, p.1395), ou seja, a desconstrução das entidades e categorias tomadas como evidências, a fim de apreender as condições que levaram às suas possibilidades. Mas nosso interesse aqui é muito mais pela questão do estilo contestatório que se delineia no horizonte de sua obra; a maneira pela qual o sujeito suporta e sustenta seu verdadeiro-dizer e a diferença de estilo para com a psicanálise. Este avesso da psicanálise representado por Foucault nos permitirá apreender a tensão que procura manter o estilo do verdadeiro-dizer analítico. Dito de outra maneira, é pela via da questão da parresia que buscaremos situar as coordenadas de uma possível postura para sustentar a causa analítica.

\section{A CRÍTICA FOUCAULTIANA À PSICANÁLISE}

Estenderemo-nos brevemente sobre a mais viva crítica elaborada por Foucault contra a psicanálise, em sua história da sexualidade. Tais críticas e as respostas que proporemos permitirão demarcar o ponto de divergência fundamental que os separam.

Foucault aponta a hipótese repressiva como um elemento dominante na retomada histórica da sexualidade. Ele denuncia uma historicização da sexualidade que passaria necessariamente pela ideia da repressão, da proibição e do silêncio. A questão colocada por Foucault não diz respeito ao porquê da sexualidade ser reprimida, ou se esta hipótese é verdadeira historicamente ou não; mas sim, porque defendemos tal hipótese com "tanta paixão". "Por qual espiral chegamos ao ponto de afirmar que o sexo é negado (...)?" (FOUCAULT, 1976, p.16). Por que, no que diz respeito ao sexo, utilizamos, como único princípio organizador, a lógica repressiva?

O sexo e sua história, segundo Foucault, seriam objetos de um mito produtor de um discurso, cujo único operador é uma lógica negativa da repressão. E a psicanálise, participa e contribui com esta narrativa de historicização da sexualidade? 
Em 1912, Freud propõe sua própria versão da historicização da sexualidade: “nas épocas em que não havia dificuldades que impedissem a satisfação sexual, como talvez tenha sido o caso durante o declínio das civilizações antigas, o amor tornava-se sem valor e a vida, vazia; foram necessárias poderosas formações reativas para restaurar os valores afetivos indispensáveis". (FREUD, 1912/1969, p.63)

O princípio aí subjacente é essencial: “é preciso haver um obstáculo para intensificar a libido”, e se este obstáculo natural falha, nós passamos a inventá-lo.

Nesta historicização freudiana da sexualidade, nota-se que o obstáculo é, portanto, inventado secundariamente para proteger da sensação de vazio de uma depressão, diante da impossível satisfação. Freud não é ingênuo acerca da hipótese repressiva. Ele a circunscreve como uma pura ficção defensiva contra o impossível. Algumas linhas adiante, o princípio é enunciado: devemos considerar a possibilidade de que "algo na própria natureza da pulsão sexual é desfavorável à realização da satisfação plena” (FREUD, 1912/1969, p.64). A castração está inscrita no coração da pulsão. Ainda, é a castração que se coloca como o verdadeiro motor desta historicização.

Lacan, como bom entendedor que é, irá formulá-lo precisamente assim, três anos antes do texto de Foucault: "Mesmo se as lembranças da repressão familiar não fossem verdadeiras, seria preciso inventá-las, e não se deixa de fazê-lo. É isso o mito, é a tentativa de dar forma épica ao que se opera pela estrutura. O impasse sexual secreta as ficções que racionalizam o impossível do qual ele provém”. (LACAN, 1973/2001, p.532)

A hipótese repressiva seria muito mais um mito secretado diante do impossível do que uma historicização sustentada pela psicanálise.

A outra crítica volta-se para a confissão enquanto "procedimento" para “produzir a verdade do sexo” (FOUCAULT, 1976, p.76). Seria a verdade necessariamente impedida e obstruída? A concepção da confissão como procedimento inevitável acaba por modelar a verdade como acorrentada e barrada por um obstáculo e um poder que pesam sobre ela. Reconhecemos aqui uma crítica a toda a dinâmica freudiana da repressão, da resistência e o correlato técnico desta cura pela palavra. Para Foucault, "é preciso estar muito iludido com esse ardil interno da confissão para atribuir à censura, à interdição de dizer e de pensar, um papel fundamental”. (Idem, p.81)

Ora, este aspecto dramático da verdade a se libertar pela confissão, este jogo de força entre verdade e censura, desaparecem com a estruturalização operada por Lacan. O meio-dizer da verdade é a consequência estrutural da disjunção entre significante e verdade - disjunção esta que não se deve a nenhum obstáculo. A resistência, dirá Lacan, é o "termo polido” para indicar “a miragem da verdade” (LACAN, 1976/2001, p.572). Tem-se a impressão, aliás, que Foucault 
toca nesta mesma ideia quando formula que "a própria forma da confissão acena [a verdade] como sendo o inacessível” (FOUCAULT, 1976, p.80). A psicanálise não será ludibriada pelo procedimento da confissão. Ao contrário, ela radicaliza o seu fracasso estrutural apresentando-o, ele também, como a máscara do impossível do tudo-dizer.

O último ponto de crítica, o mais fundamental, toca o inevitável emaranhado entre desejo e Lei que a psicanálise sustentará. Foucault critica o modelo jurídico e negativo do poder que rege a sexualidade. Por que fazer da Lei o único princípio da sexualidade?

Dirá Foucault: se é verdade que a psicanálise evita a armadilha da simples repressão social (bandeira agitada por Reich), ela reintroduz a negatividade da Lei como princípio inerente ao desejo:

“Que o sexo não seja “reprimido” não é de fato uma asserção muito nova. Já faz um bom tempo que os psicanalistas o disseram. Eles recusaram a maquinaria simples que facilmente se imagina ao falar em repressão; a ideia de uma energia rebelde a subjugar pareceu-lhes inadequada para decifrar a maneira como poder e desejo se articulam; eles os supõem ligados de modo mais complexo e mais original do que esse jogo entre uma energia selvagem, natural e viva, provinda de baixo, que aumenta sem cessar, e uma ordem que tenta lhe opor um obstáculo de cima; não se trata de imaginar que o desejo é reprimido, pela boa razão de que é a lei que é constitutiva do desejo e da falta que o instaura. A relação de poder já estaria lá onde está o desejo: ilusão, portanto, denunciá-lo numa repressão exercida a posteriori; vão, também, partir em busca de um desejo exterior ao poder." (FOUCAULT, 1976, p.79-80)

A passagem de Reich à Lacan conservaria o princípio da lei como constitutiva ao desejo. Nada se fez de diferente, a não ser deslocar o obstáculo exterior para o coração do desejo. "Vocês também já foram enganados”, diz Foucault, por um desejo que encontra uma Lei, um princípio de poder, no seu ponto de emergência. Por outro lado, critica Foucault, esta concepção do poder é bastante pobre. Por que considerar o poder como única limitação negativa? Por que eternizar uma perspectiva jurídica do poder que não pode nada além de proibir e nada produzir?

Lembremos que em Freud a censura não é a-produtiva. Se as formações do inconsciente existem, é porque existe uma censura. A censura forma e produz de acordo com a gramática dos processos primários.

Voltemos ao ponto essencial, que versa sobre a articulação entre o desejo e a Lei. A emergência do objeto a, a partir de 1962, permite frustrar a crítica foucaultiana. O objeto a causa do desejo agora substitui o pai. O objeto do desejo 
é constituído secundariamente à falta, que por sua vez é inerente à entrada na linguagem. O desejo do fala-ser não mais se origina no pai, mas na perda que se deve à linguagem. Como nos indica Colette Soler: "o gozo limitado que, desta perspectiva, já se poderia dizer castrado do falante, não é efeito de nenhum interdito”. (SOLER, 2009, p.159)

A teoria freudiana do pai e do interdito é uma ilusão acerca da verdadeira estrutura do desejo. O pai não é o agente da castração, mas aquele que protege do impossível.

Qual seria então a função paterna? O objeto a, diz Soler, causa o desejo, mas não nos indica uma resposta. Ele causa o desejo como "indeterminado e anônimo”. A causa “não diz... o desejável” (Idem, p.162). É aí que o pai passa a articular-se ao desejo, mas apenas secundariamente. O pai terá esta função de designar o desejável e, portanto, de se constituir muito mais como uma "solução para a indeterminação do desejo”. (Idem, p.163)

Mas, mesmo com o objeto a, diria um foucaultiano, a psicanálise permanece na lógica da subtração e da falta, ainda que tal objeto seja articulado à linguagem, conforme Lacan. Em última instância, diremos que a ideia denunciada por Foucault é aquela do aprisionamento na lógica da castração, o que implica uma concepção negativa e jurídica do Poder-Lei. Foucault positivará o poder para pensá-lo a partir das diferentes estratégias, móveis e múltiplas, da relação de forças. Se Foucault busca desfazer-se desta lógica, veremos quais são as consequências estilísticas às quais ele chegará ao final de sua obra.

\section{O ESTILO CONTESTATÓRIO DO CÍNICO E SEU AVESSO ANALÍTICO}

Comecemos por extrair as consequências sobre o estilo desta diferença teórica. Referimo-nos aqui unicamente aos últimos cursos de Foucault no Collège de France, entre 1982 e 1984. O desafio para Foucault, em seus estudos helenísticos, é pensar uma relação entre sujeito e verdade que não exalte o registro do conhecimento. Como o sujeito pode ligar-se a uma verdade, e a partir dela adotar uma posição ética, sem prender-se na lógica do deciframento de si? É neste contexto que Foucault convoca a noção de parresia e a figura do cínico. Ambas permitem entrever uma relação inédita entre sujeito e verdade, que passa pela bios, pelo modo de vida, pela estilística da existência. Mas, se Foucault utiliza-se destas figuras cínicas por seu valor contestatório, o que buscamos destacar aqui é o seu estilo contestatório. Este estilo, veremos, passa a atuar como uma contestação contra a castração. Como sublinhou Birman (2010), tanto Lacan quanto Foucault evidenciam a dimensão ética do sujeito, mas de maneiras diferentes. Propomos aqui examinar esta diferença e observar como o estilo ético postulado por Foucault esclarece, pelo seu avesso, o estilo analítico. 


\section{O QUE É A PARRESIA?}

A parresia, significando o "tudo-dizer" ou o "franco-falar", é a ideia de dizer a verdade sem máscara e sem ornamento, diante da instância do poder. Com esta noção, Foucault busca apreender a relação entre o sujeito e a verdade no momento que o sujeito diz a verdade sobre os outros e aos outros. A parresia, em seu aspecto social e político, terá como forma paradigmática um sujeito que, apesar do perigo que isto implica, dirige-se ao tirano para dizer-lhe a verdade na cara - esta verdade que o tirano não quer saber. Foucault assinala que a característica fundamental da parresia não está no conteúdo ou na forma do enunciado, mas no fato de que o sujeito arrisca sua vida pelo ato de defender a verdade. $\mathrm{O}$ ato de dizer tem consequências caras de exílio, exclusão, etc.

\section{A PARRESIA E A PSICANÁLISE}

Esta posição discursiva oferece, à primeira vista, certa analogia sedutora com a posição analítica. Trabalho da verdade, busca de desmascaramento, figura da exclusão — não há aí pontos em comum com a posição do analista? A psicanálise é considerada inimiga da cultura; seu discurso tende a reintroduzir a verdade reprimida do sujeito e, também, a do social. A posição analítica no social não seria a forma de uma prática de parresia, que necessita, segundo as palavras de Foucault, da "coragem da verdade" (FOUCAULT, 1984)? Sabe-se que Freud não considera a sua descoberta como fruto de certo dom intelectual particular, mas de sua coragem fáustica. Sabe-se também que, contrariamente a Breuer e Charcot, que flertaram de modo descompromissado com a coisa sexual, Freud foi quem ousou dizê-lo.

Esta aproximação é ainda mais interessante quando nos lembramos de que, com a parresia, Foucault se questiona a respeito de uma dimensão bastante particular do discurso. Não é a análise formal do discurso verdadeiro, ou do que o torna válido, que lhe interessa. Antes, é a postura subjetiva daquele que enuncia uma verdade, ou o modo de ser que este discurso impõe ao sujeito que o sustenta. Sabe-se que este é precisamente o desafio do saber analítico. Como formula Lacan: “a questão deste saber não é de forma alguma se ele articula-se ou não, a questão é saber em qual lugar é preciso estar para sustentá-lo" (LACAN, 04 nov 1971-1972). Desejo do analista, discurso do analista, ética, ou mesmo a questão do estilo, todos estes elementos vêm suprir a falha na estrutura científica transmissível da Coisa analítica.

Foucault fala da parresia e do cínico para evocar um modo de vida, uma forma de existência, uma forma de enunciado através da bios. É evidente que isto se afasta da psicanálise, que não visa criar um modo de vida. Mas o ponto comum recai sobre esta postura subjetiva e ética de um dizer-verdadeiro diante daquele 
que não quer nada saber. Logo, se evocamos certa analogia, é precisamente para compreender também toda a diferença.

Seria possível realizar uma primeira apreciação sobre a diferença abordando estas duas posturas em sua tonalidade afetiva. Foucault situa a verdade em uma montagem dramática. Esta montagem sugere que o que falta à verdade para que ela seja dita é a coragem. Esta posição, digamos de passagem, sustenta a ilusão de que a castração está ao lado do sujeito, e não ao lado do Outro. Mas ela se distancia, em sua tonalidade afetiva, da psicanálise, que busca expressar seu saber pela paródia — afeto preferido de Lacan (MILLER, 1997). Como compreender então esta diferença de tonalidade?

\section{A FIGURA DO CÍNICO - UMA POSTURA EMBLEMÁTICA DA PARRESIA}

Nesta montagem dramática, qual é a posição e o estilo do filósofo?

Foucault convoca a figura do cínico como emblemática, e a mais ruidosa, da parresia. O cínico é aquele que se utiliza da parresia para jogar a verdade-toda na cara do outro. Pelo seu modo de vida muito particular e provocador, ele se torna e indica "o escândalo da verdade". (FOUCAULT, 1984, p.161)

O cinismo é a figura de um "heroísmo filosófico” (Idem, p.195). Ele é o militante filosófico e o "missionário da verdade” (Idem, p.290). Foucault observa que esta ética e este heroísmo filosófico cessaram no início do século XIX com a última grande figura, aquela do Fausto de Goethe, quando a filosofia se tornou uma profissão de professor. Entretanto, desde então ela foi "deslocada no campo político: na vida revolucionária” (Idem, p.196) e na arte contemporânea. A arte, como o cínico de outrora, “deve estabelecer com o real uma relação que não é mais da ordem do ornamento, (...) mas que [é] da ordem do desnudamento, do desmascaramento, (...), da redução violenta ao elementar da existência" (Idem, p.173). Aqui, ainda se coloca a questão: a psicanálise deve inscrever-se nesta filiação?

Seria inexato afirmar que Foucault defende a ilusão de um tudo-dizer pelo significante. Mas a montagem discursiva cínica, devido ao fato de buscar o dizerverdadeiro pela bios, pela estilística da existência, convoca o corpo, este lugar que não é da ordem do significante, para atuar o que o significante fracassou em dizer. O corpo e a bios parecem, assim, ser convocados para contornar a castração, do fato de linguagem, do fala-ser.

\section{A ESTRUTURA PERVERSA DO CÍNICO}

Nesta perspectiva, tal postura cínica, tal montagem discursiva - e esta é nossa hipótese - afilia-se a uma posição perversa que, aliás, revela a cláusula perversa 
de toda militância. Que fique claro: não é a pessoa de Foucault que questionamos aqui, mas a montagem discursiva descrita por ele. Se o cínico se agarra tanto a uma verdade que ele quer, por um "escândalo" (FOUCAULT, 1984, p.171), comunicar, é porque, continua o filósofo, seu desejo é de curar a humanidade com esta verdade. Ele é motivado por uma "missão de cuidado”, uma "relação médica” (Idem, p.256) de devoção que implica um “sacrifício de si”. Ele é “o instrumento da felicidade dos outros".

O perverso é precisamente aquele que se atribui como missão ser "o instrumento do gozo do Outro" (LACAN, 1960/1966, p.823). Este Outro é a mãe, em que o perverso se empenha para curar da castração. O perverso, dirá Lacan, "é aquele que se consagra a tapar o buraco no Outro. (...) É um defensor da fé" (LACAN, 1968-1969, p.253). Melhor ainda, o perverso busca "restaurar (...) o Outro em sua aparente integridade” (Idem, p.382). Assim, “o S(A) fornece a chave da perversão". Nota-se então a missão curativa do ato perverso, que é precisamente aquela do cínico.

Este hino que o perverso canta para o S(A) é justamente esta mesma tentativa do cínico - este “missionário filosófico" (FOUCAULT, 1984, p.271), este "marturôn tês alêtheias" (Idem, p.160), testemunho da verdade. Ele busca sustentar a crença na plenitude do Outro, em um Outro não barrado e sem falhas.

\section{ESTILÍSTICA DA EXISTÊNCIA/ESTILO DO ANALISTA}

A psicanálise mostra que a verdade, para se expressar, passa pela fratura da censura ou pela do simbólico. Aí onde a psicanálise busca operar com a Lei da linguagem, Foucault descreve uma montagem discursiva que busca transgredi-la. É também por isso que ela será um "grau zero da retórica” (FOUCAULT, 1982-83, p.52), um discurso sem ornamento que visa dizer a verdade sem máscara. A parresia acredita poder transgredir a lei do fala-ser. Ela coloca em cena a ilusão de poder dizer uma verdade pelo significante ou, então, pelo corpo e pela bios. Ela mascara o impossível que se liga ao significante.

Diferentemente desta estilística da existência, a psicanálise convoca o estilo, pois a verdade só pode ser meio-dita ou ligeiramente tocada, justo pelo ornamento retórico, pela alusão, o equívoco do significante, a fuga de sentido e os efeitos de estilo. A regra fundamental, o tudo-dizer analítico, é o avesso do tudo-dizer parresiático. O tudo-dizer analítico provém do impossível e se origina a partir da castração. A ética do "bem dizer", esta maneira de se aproximar ao máximo do real pelo significante, encontra seu valor exatamente nisto que a define como assintótica. 


\section{FERENCZI - UMA PARRESIA ANALİTICA}

A história da psicanálise nos mostra uma figura da parresia. Trata-se de Ferenczi, que foi motivado por um verdadeiro desejo de "absoluta franqueza mútua" (FERENCZI, 1910, p.228). A sinceridade sintomática, a revolta contra a hipocrisia profissional, acabam por esconder a falta estrutural que ele tenta ultrapassar pelo tudo-dizer. Como observa Vanier:

“(...) a verdade de que fala Ferenczi, a verdade reivindicada, não é aquela do meiodizer; é o sonho de um possível tudo dizer. Esta paixão da verdade, esta sede jamais mitigada que o mobiliza e sustenta sua reivindicação, é disto que ele sofre permanentemente. Mas se ela o conduz a aproximar alguma coisa do real até o ponto de encarná-lo, ela o impede, ao mesmo tempo, de cercá-lo.” (VANIER, 2009, p.249)

Nós situaremos este terapeuta apaixonado pela psicanálise na filiação do homem da parresia.

\section{CONCLUSÃO}

Mas se a psicanálise também se ocupa com a verdade, o que seria uma parresia que integra a lógica analítica? Que estilo ela teria? Haveria uma parresia lacaniana? Contrariamente a esta militância filosófica, para Lacan é impossível tudo dizer e "é justamente por este impossível que a verdade tem a ver com o real" (LACAN, 1973/2001, p.509). Tal é o efeito pacificador da estrutura.

Mas diante do grito ruidoso do homem da parresia, haveria lugar para opor o silêncio do analista? Tal é a proposta de Wittgenstein que, diante dos limites da palavra, propõe o silêncio. Milner observa que Lacan se afasta do silêncio. "Eu, a verdade, falo" (LACAN, 1966, p.409), permite compreender que "o silêncio é, no registro do real, impossível” (MILNER, 1995, p.169). Isto sobre o que não se pode falar, não consiste em se calar, pois a verdade reprimida sempre retorna. “Impossível falar, impossível não falar. Daí, as estratégias do entre-dois, do meio-dizer, do não-tudo" (MILNER, 1995, P.169). Verdadeira "heterologia” que o objeto analítico convoca a produzir.

Se falamos de uma parresia analítica, queremos demonstrar que ela sustenta uma tensão paradoxal que a torna fecunda. É na praça pública, em "Radiofonia”, que encontraremos suas coordenadas. No momento que Lacan enuncia no rádio a verdade como limite, ele se espanta de tê-lo dito no rádio. Ele explica: "É que os que aqui [no Rádio] me escutam, ao ouvirem o que eu digo, não têm obstáculo para me entender. Onde me fica claro que esse obstáculo decorre, em outros lugares, de eu ter que calculá-lo” (LACAN, 1970/2001, p.442). Lacan assume seu espanto ao proferir tamanho escândalo no rádio. Mas se ele se autoriza a dizê-lo 
é porque seu público do rádio não escuta o que ele diz - enquanto que, diante de um auditório preparado, ele se arrisca, paradoxalmente, a ser escutado e a se confrontar com o obstáculo do horror ao saber. Diante da cultura, seu discurso se desinibe, indo ainda mais longe do que quando diante do auditório, pois se encontra protegido pela sua incompreensão.

Lacan comenta sobre esta cena surpreendente em que a fala lhe escapou. É “um dos métodos com que se poderia agir sobre a cultura. Quando se é tomado por acaso no nível de um público amplo, por que justamente não elevar o nível, proporcionalmente à inaptidão presumida? Por que diminuir o tom?" (LACAN, 1969-70, p.214-215, [grifo nosso]). Lacan desempenha aí um ato de parresia na cultura. Ora, este ato é possível, pois reabre uma defasagem e instaura um princípio de impossível. Se, neste caso, o obstáculo não é o horror do saber, Lacan reinjeta o obstáculo pela inacessibilidade de seu discurso. O que é bem o seu estilo, tendo em vista a sua conduta pessoal. Mas o derradeiro desafio é o de adotar uma posição cujo foco seja o impossível. Se a psicanálise é uma das três “profissões impossíveis" (FREUD, 1937, 1985), é na medida em que "deve integrar em seu ato o pensamento estrutural de uma in-suficiência do efeito produzido" (ASSOUN, 2007).

Entre o bem dizer e o impossível de dizer se desenha uma tensão paradoxal que é própria ao estilo analítico. Tal tensão não acredita na possibilidade da última palavra, mas, ao mesmo tempo, não goza, através do silêncio, do impossível. Ao contrário, o impossível de dizer é uma condição necessária que relança o bem dizer. O estilo do dizer segue assim a dinâmica do desejo, pois, como o desejo, ele é causado por um ponto de falta.

Recebido em 28/3/2013. Aprovado em 20/5/2013.

\section{REFERÊNCIASS}

ASSOUN, P.-L. (2007) Du métier impossible à l'acte nécessaire, l'effet analytique. Figures de la psychanalyse, n.15, 1, 17-31.

BIRMAN, J. (2010) Le dire vrai et la psychanalyse: à propos de Foucault et Lacan. Recherche en psychanalyse, n.9, 63-72.

FERENCZI, S. (1910/1992) Sigmund Freud, Sandor Ferenczi correspondance t. I 1908-1914. Paris: Calmann-Lévy.

FOUCAULT, M. (1976) Histoire de la sexualité 1, La volonté de savoir. Paris: Gallimard.

(1982-83/2008) Le gouvernement de soi et des autres, cours au collège de France 1982-1983. Paris: Gallimard. 
(1984/2009) Le courage de la vérité, Le gouvernement de soi et des autres II, Cours au collège de France. Paris: Gallimard.

(1984/2001) “Que ce que les Lumières ?”, in Dits et écrits II, 1976-1988. Paris: Gallimard. p.1379-1403.

FREUD, S. (1912/1969) “Sur le plus général des rabaissements de la vie amoureuse", in La vie sexuelle. Paris: PUF, p.55-65.

(1937/1985) “L'analyse avec fin et l'analyse sans fin”, in

Résultats, idées problèmes II, Paris: PUF, p.231-268.

LACAN, J. (1966) Ecrits. Paris: Seuil.

(1968-69/ 2006) Le Séminaire livre XVI, D’un Autre à l'autre 1968-

1969. Paris: Seuil.

. (1969-70/1991) Le Séminaire livre XVII, L'envers de la psychanalyse,

1969-1970. Paris: Seuil.

. (1971-1972) Le savoir du psychanalyse, inédit.

(2001) Autres écrits, Paris: Seuil.

MILLER, J.-A. (1997) Seminario - el deseo de Lacan. Atuel-Anàfora.

MILNER, J.-C. (1995) L'oeuvre claire, Lacan, la science, la philosophie. Paris: Seuil.

SOLER, C. (2009) Lacan, l'inconscient réinventé. Paris: PUF.

VANIER, A. (2009) “Conclusion: avec Ferenczi et avec Lacan”, in GOROG, J. J. (Org.) Ferenczi après Lacan. Paris: Hermann.

Amos Squverer

a.squverer@gmail.com 